\title{
Mechanism of Bilirubin Diglucuronide
}

\section{Formation in Intact Rats}

\author{
BILIRUBIN DIGLUCURONIDE FORMATION IN VIVO
}

\author{
Norbert Blanckaert, John Gollan, and Rud Schmid, Department of Medicine \\ and Liver Center, University of California School of Medicine, San Francisco, \\ California 94143; Laboratory of Hepatology, Department of Medical Research, \\ University of Leuven, B-3000, Leuven, Belgium
}

\begin{abstract}
A B S T RA C T Although it is well established that bilirubin monoglucuronide is formed in the liver from bilirubin by a microsomal bilirubin uridine diphosphate (UDP)-glucuronosyltransferase, the subcellular site of conversion of monoglucuronide to diglucuronide and the molecular mechanism involved in diglucuronide synthesis have not been identified. Based on in vitro studies, it has been proposed that two fundamentally different enzyme systems may be involved in diglucuronide synthesis in rat liver: $(a)$ a microsomal UDP-glucuronosyltransferase system requiring UDPglucuronic acid as sugar donor or $(b)$ a transglucuronidation mechanism that involves transfer of a glucuronosyl residue from one monoglucuronide molecule to another, catalyzed by a liver plasma membrane enzyme. To clarify the mechanism by which bilirubin monoglucuronide is converted in vivo to diglucuronide, three different experimental approaches were used. First, normal rats were injected with either equal amounts of bilirubin-III $\alpha\left[{ }^{14} \mathrm{C}\right]$ monoglucuronide and unlabeled bilirubin-XIII $\alpha$ monoglucuronide, or bilirubin-XIII $\alpha\left[{ }^{14} \mathrm{C}\right]$ monoglucuronide and unlabeled bilirubin-III $\alpha$ monoglucuronide. Analysis of radiolabeled diglucuronide excreted in bile showed that $\left[{ }^{14} \mathrm{C}\right]-$ glucuronosyl residues were not transferred between monoglucuronide molecules. Second, in normal rats infused intravenously with dual-labeled $\left[{ }^{3} \mathrm{H}\right]$ bilirubin
\end{abstract}

This work was presented in part at the 79th Annual Meeting of the American Gastroenterology Association 22-25 May 1978. Gastroenterology. 74: 1166. (Abstr.)

Dr. Blanckaert is an Appointed Investigator of the Belgian National Research Council and a grantee of a North Atlantic Treaty Organization research fellowship and Senior Fulbright-Hays scholarship. Address reprint requests to Dr. Blanckaert in California.

Received for publication 24 August 1979 and in revised form 7 February 1980. $\left[{ }^{14} \mathrm{C}\right]$ monoglucuronide, no transfer or exchange of the $\left[{ }^{14} \mathrm{C}\right]$ glucuronosyl group between injected and endogenously produced bilirubin monoglucuronide could be detected in the excreted bilirubin diglucuronide. Third, in homozygous Gunn rats, injected ${ }^{14} \mathrm{C}$ labeled or unlabeled bilirubin mono- or diglucuronides were excreted in bile unchanged (except that diglucuronide was hydrolyzed to a minor degree). This indicates that Gunn rats, which lack bilirubin UDPglucuronosyltransferase activity, are unable to convert injected monoglucuronide to diglucuronide. Collectively, these findings establish that a transglucuronidation mechanism is not operational in vivo and support the concept that bilirubin diglucuronide is formed by a microsomal UDP-glucuronosyltransferase system.

\section{INTRODUCTION}

Bilirubin, ${ }^{1}$ the principal degradation product of heme in mammals (1), is excreted in bile largely in the form of polar derivatives in which one or both propionic acid $\beta$-substituents of the pigment are esterified with a sugar, predominantly glucuronic acid $(2,3)$. This conjugation is thought to disrupt the multiple intramolecular hydrogen bonds responsible for the nonpolar character of bilirubin and thereby renders the pigment excretable in bile (4). It is well established that formation of bilirubin monoglucuronide (BMG) is catalyzed by microsomal uridine diphosphate (UDP)glucuronosyltransferase [UDP-glucuronate $\beta$-glucuronosyltransferase (acceptor unspecific), EC 2.4.1.17], with UDP-glucuronic acid (UDPGlcUA) serving as sugar donor (5). It remained unexplained, however,

\footnotetext{
${ }^{1}$ Abbreviations used in this paper: bilirubin, bilirubin-IX $\alpha$; BDG, bilirubin diglucuronide; BMG, bilirubin monoglucuronide; TLC, thin-layer chromatography; UDP, uridine diphosphate; UDPGICUA, uridine diphosphate glucuronic acid.
} 
why on incubation of liver homogenate or microsomes from humans, rats, dogs, and cats with UDPGlcUA, the reaction product was largely BMG (6), while in these species bile contains predominantly bilirubin diglucuronide (BDG) $(2,3,7-9)$. Because of this apparent inconsistency between the findings in vivo and in vitro, it has been postulated that conversion of BMG to BDG is catalyzed by a separate enzyme that differs from bilirubin UDP-glucuronosyltransferase. Recently, it has been reported that in rat liver, synthesis of BDG from BMG is catalyzed by BMG glucuronosyltransferase, an enzyme which is distinct from microsomal UDP-glucuronosyltransferase in its reaction mechanism and subcellular location (10). This enzyme is believed to convert BMG to BDG by transfer of a glucuronsyl group from one BMG molecule to another, whereby 1 mol of bilirubin and $1 \mathrm{~mol}$ of BDG are formed from 2 mol of BMG. This transglucuronidation reaction does not require UDPGlcUA as sugar donor, and the enzyme involved exhibits highest specific activity in the plasma membrane fraction. The reported reaction rate of $\mathrm{BMG}$ glucuronosyltransferase in rat and human liver far exceeds that of microsomal bilirubin UDP-glucuronosyltransferase. An unimpaired rate of conversion of B.MG to BDG in vitro has been observed in liver preparations from patients with Crigler-Najjar disease type 1 and from homozygous Gunn rats (11), both of which lack detectable hepatic bilirubin UDP-glucuronosyltransferase activity.

Several well-established observations in humans and rats in vivo have indicated that, in the presence of either a high hepatic bilirubin concentration or reduced microsomal bilirubin UDP-glucuronosyltransferase activity, the liver preferentially forms BMG $(9,12-16)$. Therefore, we examined the microsomal UDP-glucuronosyltransferase system of rat liver to see whether, under the standard assay conditions, the preferential formation of B.MG is related to the unphysiologically high bilirubin substrate concentrations used. We found that when the pigment substrate concentration in the incubation medium was substantially decreased, liver microsomes form approximately equal amounts of BMG and $B D G$ from bilirubin and readily convert added BMG to BDG (17). Both reactions are critically dependent on UDPGlcUA, as neither liver homogenate nor microsomes convert bilirubin or BMG to BDG in the absence of added UDPGlcUA. Moreover, synthesis in vitro of BDG from BMG was found to be deficient in homozygous Gunn rats. These findings in vitro suggested that formation of both BMG and BDG is catalyzed by a microsomal UDP-glucuronosyltransferase system, distinct from BMG glucuronosyltransferase.

Conflicting results have also been reported on the conversion of BMG to BDG in vivo. Whereas Ostrow and Murphy (18) could not detect conversion of injected BMG to BDG in homozygous Gunn rats, Chowdhury et al. (11) reported formation of BDG from administered BMG in amounts comparable to those in normal rats.

The present study was undertaken to clarify the mechanism of BDG formation in vivo. Experiments were devised to examine whether BDG is synthesized in vivo in normal rats by transglucuronidation of BMG, and whether homozygous Gunn rats can convert administered BMG to BDG.

\section{Experimental approach}

In intact normal rats we carried out two different types of experiments designed to detect transfer of glucuronosyl residues between BMG molecules (transglucuronidation). The first approach (series I) was based on the dissymmetry of bilirubin, which is due to the different sequence of the methyl and vinyl $\beta$-substituents on the outer pyrrolinone rings. The molecule thus contains two dissimilar dipyrrylmethenes, which we shall designate as $\mathbf{A}$ (with endovinyl side chain) and B (with exovinyl side chain), respectively. For convenience the complete molecule is denoted as A-B (Fig. 1). Bilirubin monoglucuronide therefore exists in two isomeric forms that differ by the attachment of the sugar moiety to either the A or the B dipyrrylmethene. ${ }^{2}$ Both isomers are formed when liver homogenate or microsomes are incubated with bilirubin and UDPGlcUA $(17,19)$, and both have been identified in rat bile $(8,9)$. For unknown reasons, the monoglucuronide conjugated in A usually predominates $(9,17,19)$.

If BDG were formed by a transglucuronidation mechanism, ${ }^{14} \mathrm{C}$-labeled glucuronosyl groups for example, attached exclusively to dipyrrylmethene $A$ of injected $B M G$ would be transferred to both the $A$ and $B$ halves of other BMG molecules. However, since the two isomeric bilirubin monoglucuronides have not been isolated or synthesized individually, BMG with a radiolabeled conjugating group attached exclusively to either the A or B dipyrrylmethene is not available. We therefore used as model compounds the radiolabeled monoglucuronides of the symmetrical bilirubin-III $\alpha$ and -XIII $\alpha$ (Fig. 1). Since each of these molecules contains either two B or two A dipyrrylmethenes, the radiolabeled glucuronosyl group is attached solely to B in the III $\alpha$ and to A in the XIII $\alpha$ isomer. Physiologically, the bilirubin-III $\alpha$ and -XIII $\alpha$ isomers and their monoglucuronides behave similarly to the corresponding IX $\alpha$ isomers (Results).

Rats provided with an external bile fistula were injected intravenously with a mixture of equal amounts of bilirubin-XIII $\alpha\left[{ }^{14} \mathrm{C}\right]$ monoglucuronide $[\mathrm{A}-(\mathbb{A} *]$ and

\footnotetext{
${ }^{2}$ Trivial names proposed for these two isomers are bilirubin C-8 monoglucuronide, corresponding to the isomer that carries the glucuronosyl group on the dipyrrylmethene part A, and bilirubin C-12 monoglucuronide, corresponding to the opposite isomer.
} 

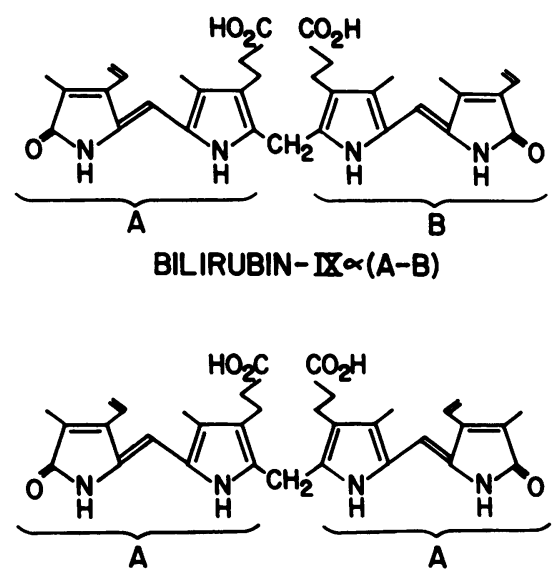

BILIRUBIN-XIII $\alpha(A-A)$

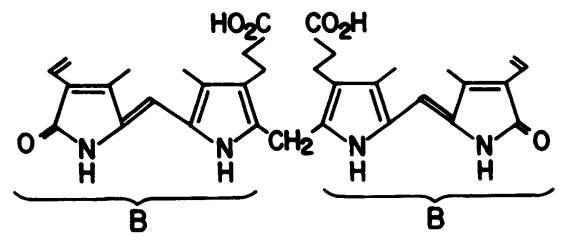

BILIRUBIN-III $\propto(B-B)$

FIGURE 1 Structure of bilirubin-IX $\alpha$, -XIII $\alpha$, -III $\alpha$. Bilirubin contains two different dipyrrylmethene moieties, $A$ and B, linked by a central methylene bridge; $A$ and $B$ differ by the presence of an endovinyl group in $A$ and an exovinyl group in B. Consequently, the dissymmetrical bilirubin can be denoted as A-B, and the symmetrical molecules bilirubin-III $\alpha$ and -XIII $\alpha$ as B-B and A-A, respectively.

unlabeled bilirubin-III $\alpha$ monoglucuronide[B-(B]. Other animals were given equal amounts of bilirubin-III $\alpha$ $\left[{ }^{14} \mathrm{C}\right]$ monoglucuronide [B-(B)*] and unlabeled bilirubinXIII $\alpha$ monoglucuronide [A-@] (Fig. 2). The BDG excreted in the bile was isolated and the proportion of $\left[{ }^{14} \mathrm{C}\right]$ glucuronosyl groups attached to its A or B dipyrrylmethene part was determined. If $B D G$ were formed by a microsomal, UDPGlcUA-dependent glucuronosyltransferase, all radiolabel in the excreted BDG would still be attached to the same dipyrrylmethene it had been attached to in the injected $\left[{ }^{14} \mathrm{C}\right]$ monoglucuronide. If, on the other hand, $\left[{ }^{14} \mathrm{C}\right]$ glucuronosyl groups had been transferred from the injected radiolabeled monoglucuronide to other administered or endogenous unlabeled monoglucuronide molecules, this transglucuronidation would be reflected by the occurrence of ${ }^{14} \mathrm{C}$ label on both $\mathrm{A}$ and $\mathrm{B}$ dipyrrylmethenes in the excreted BDG.

In Fig. 2, two different schemes are presented for predicting transfer of radiolabel from injected $\left[{ }^{14} \mathrm{C}\right]-$ monoglucuronide to other monoglucuronide molecules by a hypothetical transglucuronidation mechanism. In both schemes it is assumed that $40 \%$ of the injected a

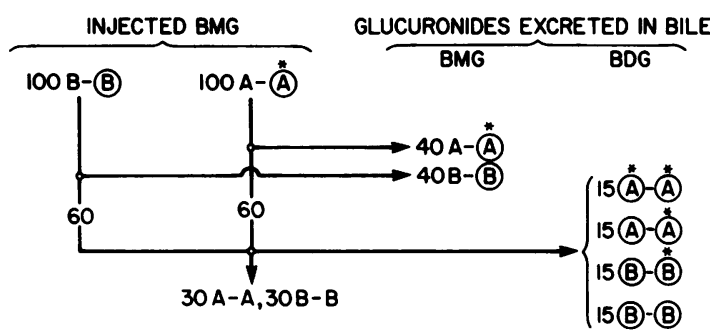

b

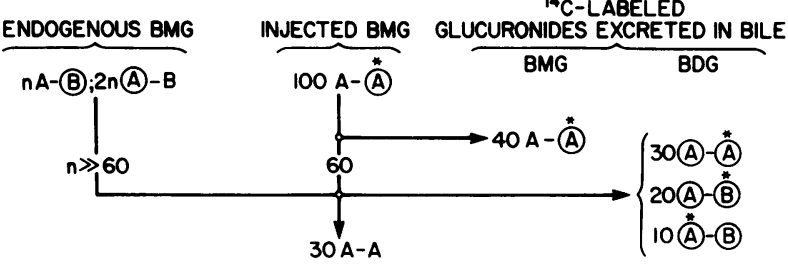

FIGURE 2 Schemes predicting the distribution of ${ }^{14} \mathrm{C}$-labeled glucuronosyl residues between dipyrrylmethenes $A$ and $B$ of BDG excreted in bile if a transglucuronidation mechanism were operational in vivo. A and B (Fig. 1) are encircled when esterified with glucuronic acid, and an asterisk indicates that the glucuronosyl group is ${ }^{14} \mathrm{C}$-labeled. In both schemes it is assumed that $40 \%$ of the injected BMG is directly excreted unchanged in bile, and that $60 \%$ undergoes transglucuronidation. This assumption is required to fit the values for BMG $(57 \%)$ and BDG $(43 \%)$ excretion predicted by transglucuronidation (Fig. 3) to the experimental findings (Tables I and III, Fig. 4). Scheme a depicts the expected fate of injected BMG when a mixture of 100 molecules of bilirubin-XIII $\alpha\left[{ }^{14} \mathrm{C}\right]$ monoglucuronide [A- (1)*] and 100 molecules of unlabeled bilirubinIII $\alpha$ monoglucuronide [B-(B)] were injected into a normal rat, assuming that BDG is formed by a transglucuronidation mechanism and that exogenous BMG far exceeds or does not mix with endogenous BMG. Under these conditions, the predicted distribution of ${ }^{14} \mathrm{C}$ label between $\mathrm{A}$ and $\mathrm{B}$ of $\mathrm{BDG}$ excreted in bile would be $75 \%$ in $\mathrm{A}$ and $25 \%$ in $\mathrm{B}$. If a mixture of bilirubin-III $\alpha\left[{ }^{14} \mathrm{C}\right]$ monoglucuronide and bilirubin-XIII $\alpha$ monoglucuronide were injected, the expected distribution of ${ }^{14} \mathrm{C}$ label in BDG would be $25 \%$ in $\mathrm{A}, 75 \%$ in $\mathrm{B}$. Scheme b shows the expected fate of the $\left[{ }^{14} \mathrm{C}\right]$ glucuronosyl groups of injected bilirubin-XIII $\alpha \quad\left[{ }^{14} \mathrm{C}\right]$ monoglucuronide in a transglucuronidation reaction in which endogenous BMG far exceeds the injected BMG. For the purpose of calculation, it is assumed that the C-8 isomer (esterified on the dipyrrylmethene part A) constitutes $67 \%$ of total endogenous BMG (9). The predicted distribution of ${ }^{14} \mathrm{C}$ label between $\mathrm{A}$ and $\mathrm{B}$ of BDG in bile is $67 \%$ in $A$ and $33 \%$ in B. On the other hand, if bilirubin-III $\alpha\left[{ }^{14} \mathrm{C}\right]$ monoglucuronide were injected, the expected distribution of ${ }^{14} \mathrm{C}$ label in BDG would be $17 \%$ in $\mathrm{A}$ and $83 \%$ in $\mathrm{B}$.

BMG is excreted unchanged in bile, whereas $60 \%$ undergoes transglucuronidation. The rationale for selecting these values is given in the legend to Fig. 3 . The two schemes differ by being based on two mutually exclusive assumptions; $(a)$ that transglucuronidation takes place either solely between the injected bilirubin-III $\alpha$ and -XIII $\alpha$ monoglucuronides without participation of endogenous BMG (Fig. 2a) or (b) that 


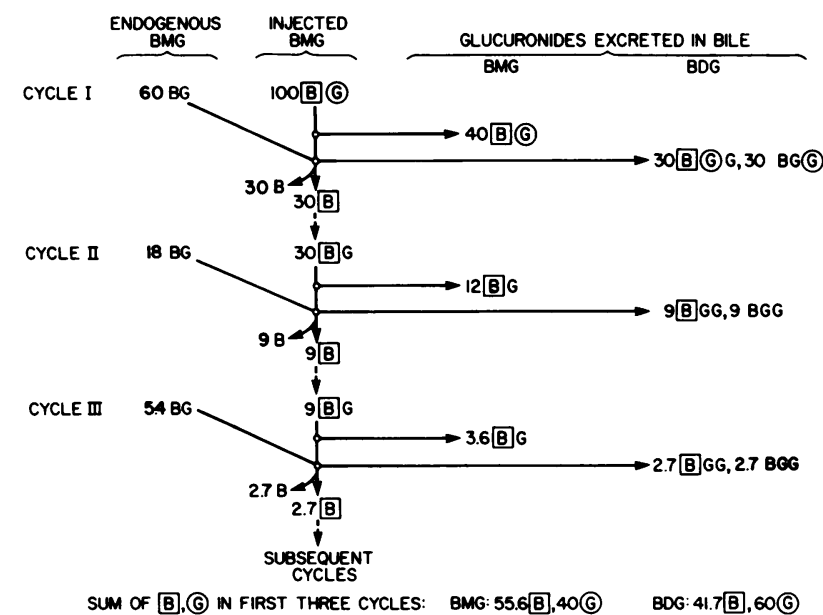

FIgure 3 Calculation of the ${ }^{14} \mathrm{C}:{ }^{3} \mathrm{H}$ ratio in $\mathrm{BMG}$ and $\mathrm{BDG}$ in bile after administration of $\left[{ }^{3} \mathrm{H}\right]$ bilirubin $\left[{ }^{14} \mathrm{C}\right]$ monoglucuronide to normal rats, assuming that transglucuronidation of BMG occurs. Symbols in the scheme are as follows: $\mathrm{B}$, unconjugated bilirubin or bilirubin aglycone; (a), glucuronosyl residue; $\mathrm{B}$, unconjugated $\left[{ }^{3} \mathrm{H}\right]$ bilirubin or $\left[{ }^{3} \mathrm{H}\right]$ bilirubin aglycone; (6), ${ }^{14} \mathrm{C}$-labeled glucuronosyl moiety. Thus, B denotes unconjugated bilirubin, BG bilirubin monoglucuronide, BGG bilirubin diglucuronide. Based on the assumption that injected $\mathrm{BMG}$ is converted to BDG by a transglucuronidation mechanism, the scheme predicts that after an infinite number of cycles about $57 \%$ of the injected BMG would be excreted in bile in the form of $B M G$ and $43 \%$ as BDG. The calculated ${ }^{14} \mathrm{C}:{ }^{3} \mathrm{H}$ ratio (expressed as a fraction of the ratio in the administered BMG) in BMG and BDG would be 0.72 and 1.44 , respectively, and the predicted isotope distribution between BMG and BDG in bile would be $57 \%$ of the ${ }^{3} \mathrm{H}$ in $\mathrm{BMG}$ and $43 \%$ in $\mathrm{BDG}$, and $40 \%$ of the ${ }^{14} \mathrm{C}$ in $\mathrm{BMG}$ and $60 \%$ in $\mathrm{BDG}$

transglucuronidation occurs exclusively between an injected III $\alpha$ or XIII $\alpha$ monoglucuronide and endogenous BMG molecules (Fig. 2b). The former assumption would hold if the amount of injected monoglucuronide far exceeded the endogenous BMG production, or if the endogenous and exogenous monoglucuronides did not mix. The latter assumption would apply if the injected monoglucuronide represented a true tracer dose relative to the endogenous BMG formation. The two schemes predict different values for the distribution of ${ }^{14} \mathrm{C}$ label between dipyrrylmethenes $\mathrm{A}$ and $\mathrm{B}$ of excreted BDG representing the extremes if either of the above assumptions were correct to the exclusion of the other. If transglucuronidation were to occur under the actual experimental conditions used, the expected distribution of $\left[{ }^{14} \mathrm{C}\right]$ glucuronosyl groups between A and B in BDG by definition would lie somewhere between these two extreme values.

In a second approach (series II), we used dual-labeled bilirubin monoglucuronide, containing ${ }^{3} \mathrm{H}$ in the tetrapyrrolic aglycone and ${ }^{14} \mathrm{C}$ in the glucuronosyl moiety. This was injected intravenously with a much larger amount of unlabeled bilirubin into rats provided with an external bile fistula, and BMG and BDG excreted in bile were isolated and analyzed. If BDG were formed from injected BMG by a UDPGlcUA-dependent microsomal glucuronosyltransferase, the ${ }^{14} \mathrm{C}:{ }^{3} \mathrm{H}$ ratio in both the excreted BMG and BDG would be the same as in the injected pigment. On the other hand, if injected BMG were converted to BDG by a transglucuronidation mechanism, $\left[{ }^{14} \mathrm{C}\right]$ glucuronic acid would be transferred from the dual-labeled BMG to other, unlabeled BMG molecules. The excreted BDG, therefore, would exhibit a higher ${ }^{14} \mathrm{C}:{ }^{3} \mathrm{H}$ ratio and the BMG a lower isotopic ratio than that in the administered pigment. In Fig. 3, a scheme is presented for predicting the isotope ratio of the excreted BMG and BDG formed by a transglucuronidation mechanism. This scheme is predicated on the administration of 100 molecules of dual-labeled $\mathrm{BMG}$ with a ${ }^{14} \mathrm{C}:{ }^{3} \mathrm{H}$ ratio of unity. It assumes that $40 \%$ of the injected BMG is directly excreted unchanged in bile, and that $60 \%$ undergoes transglucuronidation (Fig. 3, cycle I). This assumption is required to fit the values for BMG (57\%) and BDG (43\%) excretion predicted by the transglucuronidation scheme (Fig. 3) to the experimental findings (Tables I and III, Fig. 4). Whereas transglucuronidation of the dual-labeled BMG involves an infinite number of sequential cycles, all ${ }^{14} \mathrm{C}$-labeled glucuronosyl residues by definition end up in labeled BDG during the first cycle and are eliminated in bile. Exchange of labeled glucuronosyl groups occurs almost exclusively between radiolabeled BMG and unlabeled BMG because of the excess of endogenous BMG formed from the injected bilirubin. Of the 60 radiolabeled BMG molecules that enter the first transglucuronidation cycle, 30 receive a second unlabeled glucuronosyl group and 30 donate their ${ }^{14} \mathrm{C}$-labeled conjugating moiety to unlabeled BMG. The resulting 30 unconjugated $\left[{ }^{3} \mathrm{H}\right]$ bilirubin molecules are then converted to $\left.{ }^{3} \mathrm{H}\right] \mathrm{BMG}$ by UDPglucuronosyltransferase and enter a second transglucuronidation cycle. The scheme predicts that of the radioactivity in dual-labeled BMG molecules undergoing three transglucuronidation cycles, $57 \%$ of the ${ }^{3} \mathrm{H}$ appears in BMG and $43 \%$ in BDG; for the ${ }^{14} \mathrm{C}$ the expected distribution is $40 \%$ in BMG and $60 \%$ in BDG (Fig. 3). The predicted ratio of ${ }^{14} \mathrm{C}:{ }^{3} \mathrm{H}$ in $\mathrm{BMG}$ is 0.72 and in BDG 1.44 of that in the administered duallabeled BMG. These values would not be altered appreciably if cycles beyond the third were to be considered.

In a third series of experiments (series III), we examined the controversial issue of whether homozygous Gunn rats, which are unable to form BMG $(20,21)$, can convert administered BMG to BDG by transglucuronidation $(11,18)$. The animals were injected with $16-600 \mathrm{nmol}$ of unlabeled or ${ }^{14} \mathrm{C}$-labeled $\mathrm{BMG}$, with the isotope in the tetrapyrrolic aglycone, and the BMG 
and BDG excreted in bile were determined. Since transglucuronidation of BMG may be impeded by the high concentration of bilirubin in Gunn rat liver, we also examined the possibility of reverse transglucuronidation, i.e., BDG + bilirubin $\rightarrow 2$ BMG; such a reaction has been claimed to occur in normal rat liver in vitro (22). Thus, a large amount of unlabeled BDG (8.5 $\mu \mathrm{mol})$ was infused into intact Gunn rats whose endogenous bilirubin pool had been prelabeled with $\left[{ }^{14} \mathrm{C}\right]-$ bilirubin. Under these conditions, reverse transglucuronidation should result in biliary excretion of ${ }^{14} \mathrm{C}$ labeled BMG exhibiting a specific activity one-half that of the $\left[{ }^{14} \mathrm{C}\right]$ bilirubin in the animal's miscible bilirubin pool.

\section{METHODS}

The following chemicals were used: bilirubin, containing at least $92 \%$ IX $\alpha$ isomer (Merck Chemical Div., Merck \& Co., Rahway, N. J.); UDP-[U- $\left.{ }^{14} \mathrm{C}\right]$ glucuronic acid, $231 \mathrm{mCi} / \mathrm{mmol}$, $\delta$-amino $\left[4-{ }^{-14} \mathrm{C}\right]$ levulinic acid, $55-58 \mathrm{mCi} / \mathrm{mmol}$, and $\delta$-amino $\left[3,5-{ }^{3} \mathrm{H}\right]$ levulinic acid, $1.2 \mathrm{Ci} / \mathrm{mmol}$ (New England Nuclear, Boston, Mass.). Other reagents were as specified elsewhere (17). For thin-layer chromatography (TLC) glass plates precoated with silica gel were used $\left(60 \mathrm{~F}_{254}, 5765 / 0025\right.$; Merck Chemical Div.).

\section{General methods}

Preparation of pigments. $\quad\left[{ }^{14} \mathrm{C}\right] \mathrm{Bilirubin}$ and $\left[{ }^{3} \mathrm{H}\right]$ bilirubin were prepared biosynthetically (23). Unlabeled and ${ }^{14} \mathrm{C}$-labeled bilirubin-III $\alpha$ and -XIII $\alpha$ were synthesized by acidcatalyzed isomerization of commercial bilirubin or $\left[{ }^{14} \mathrm{C}\right]$ bilirubin, respectively, and isolated by TLC (24); the purity of the isolated III $\alpha$ and XIII $\alpha$ isomers was established by analytical TLC with chloroform/acetic acid, 99:1 ( $\mathrm{vol} / \mathrm{vol})$ as solvent, using authentic bilirubin-III $\alpha$, -IX $\alpha$, and -XIII $\alpha$ as references and by chromatographic analysis of the methyl esters of their ethyl anthranilate azoderivatives (25). Unlabeled bilirubin 1 - $O$-acyl- $\beta$-D-mono- and diglucuronide were purified from rat bile and isolated by TLC (17). Bilirubin-III $\alpha$ or -XIII $\alpha$ 1-Oacyl- $\beta$-D- $\left[\mathrm{U}-{ }^{14} \mathrm{C}\right] \mathrm{monoglucuronide}$ and $\left[{ }^{3} \mathrm{H}\right] \mathrm{bilirubin} 1-O$ acyl- $\beta$-D-[U- $\left.{ }^{14} \mathrm{C}\right]$ monoglucuronide were prepared biosynthetically by incubation of the corresponding bilirubin isomers or $\left[{ }^{3} \mathrm{H}\right]$ bilirubin with ${ }^{14} \mathrm{C}$-labeled UDPGlcUA and microsomes from liver of normal rats, pretreated for 4 days with intraperitoneal glutethimide $(7.5 \mathrm{mg} / 100 \mathrm{~g}$ body $\mathrm{wt})$. The other components of the incubation mixture and the isolation of the product have been described (26); the yield of BMG was 20$30 \%$. Identical incubation conditions were used for synthesis of $\left[{ }^{14} \mathrm{C}\right] \mathrm{BMG}$ or $\left[{ }^{3} \mathrm{H}\right] \mathrm{BMG}$ from $\left[{ }^{14} \mathrm{C}\right]$ bilirubin or $\left[{ }^{3} \mathrm{H}\right]$ bilirubin, and of $\left[{ }^{14} \mathrm{C}\right]$ bilirubin-III $\alpha$ monoglucuronide or $\left[{ }^{14} \mathrm{C}\right]$ bilirubinXIII $\alpha$ monoglucuronide from the corresponding $\left[{ }^{14} \mathrm{C}\right]$ bilirubin isomer, except for replacement of ${ }^{14} \mathrm{C}$-labeled UDPGlcUA by $5 \mathrm{mM}$ unlabeled UDPGlcUA. All BMG used was isolated by TLC. As reported (17), such preparations contain $80-90 \%$ authentic BMG, small amounts of BDG (5-16\%), and unconjugated bilirubin (1-8\%). The latter two pigment fractions are formed by dipyrrole exchange of BMG during TLC, as evidenced by two-dimensional TLC of the BMG preparation and analysis of III $\alpha, \mathrm{IX} \alpha$, and XIII $\alpha$ isomers. "Authentic BMG" is used throughout to denote the actual bilirubin monoglucuronide content of a given BMG preparation. In the BDG preparations, neither bilirubin nor BMG was detectable. After TLC, bilirubin glucuronides were eluted from silica gel with methanol and $A_{450}$ was measured on an aliquot of the eluate. A known volume of the eluate was immediately evaporated to dryness under reduced pressure and the residue was dissolved in normal rat serum immediately before injection. Unconjugated bilirubin-III $\alpha$, -IX $\alpha$, or -XIII $\alpha$ was dissolved in chloroform and $A_{452}$ was measured on an aliquot of the solution. A known volume of the solution was evaporated to dryness, the pigment residue was dissolved in a small volume of $0.1 \mathrm{M} \mathrm{NaOH}$ and then added to normal rat serum. The amount of injected pigment was determined spectrophotometrically, using reported $\epsilon_{452}$ values for bilirubin isomers in chloroform (24), and assuming $\epsilon_{450} 60 \times 10^{3}$ liters $\cdot \mathrm{mol}^{-1} \cdot \mathrm{cm}^{-1}$ for BMG or BDG in methanol.

Animal procedures. "Normal rats" were Sprague-Dawley (380-450 g; Simonsen Labs., Gilroy, Calif.) or male Wistar R/A 300-350 g; University of Leuven, Belgium), in which bilirubin conjugates in bile are predominantly $(71 \%)$ in the diconjugated form and glucuronides constitute $95-98 \%$ of the bilirubin conjugates (9). "Gunn rats" were male homozygous Gunn rats (300-450 g) from the University of California School of Medicine, San Francisco, or the University of Leuven. A jugular vein and the bile duct were cannulated with Intramedic polyethylene PE-10 and PE-50, respectively (ClayAdams Div., Becton, Dickinson \& Co., Parsippany, N. J.), the animals placed in restraining cages under infrared heating lamps, and infused intravenously $(2 \mathrm{ml} / \mathrm{h}$ ) with a $5 \%(\mathrm{wt} / \mathrm{vol})$ glucose solution in $0.15 \mathrm{M} \mathrm{NaCl}$ for $2 \mathrm{~h}$. Only rats producing at least $1 \mathrm{ml}$ of bile/ $\mathrm{h}$ were used. Test pigment solutions then were either injected as an intravenous bolus $(0.8-1.2 \mathrm{ml})$ or infused $(2 \mathrm{ml})$ over $15 \mathrm{~min}$. Bile was collected in tared tubes placed in ice and bile flow was determined gravimetrically. Additional details regarding specific experiments are outlined below.

Analytical procedures. In all experiments, an aliquot of the pigment solution administered to rats was analyzed simultaneously with and by the same method(s) as bile samples; when radiolabeled pigments were injected, carrier pigments in the form of rat bile, enriched with bilirubin, were added to the samples before analysis. Total bilirubin was determined by the $p$-iodoaniline procedure (27), and the ethyl anthranilate (27) and alkaline methanolysis (9) methods were used for analysis of mono- and diconjugates. When the pigments contained radiolabel in the conjugating sugar, a third procedure (28) was used in which the intact bilirubin conjugates were extracted and mono- and diglucuronides isolated by TLC using a chloroform/methanol/water, 10:5:1 ( $\mathrm{vol} / \mathrm{vol} /$ vol) solvent system; with this chromatographic procedure, isomeric forms (III $\alpha$, IX $\alpha$, and XIII $\alpha$ ) of BMG and BDG are not separable. For determination of radioactivity in isolated BMG or BDG, a known portion of the pigment band was scraped into a counting vial and the remainder was used for structural analysis and quantitation of BMG and BDG. Azoderivatives were prepared by mixing the scraped silica gel with $1 \mathrm{vol}$ of methanol and $1 \mathrm{vol}$ of diazotized ethyl anthranilate reagent (27). After $10 \mathrm{~min}$ at $20-25^{\circ} \mathrm{C} 1 \mathrm{vol}$ of ascorbic acid solution $(10 \mathrm{mg} / \mathrm{ml})$ and $5 \mathrm{vol}$ of glycine/ $\mathrm{HCl}$ buffer, $\mathrm{pH} 2.7$, ( $0.4 \mathrm{M} \mathrm{HCl}$ adjusted to $\mathrm{pH} 2.7$ with solid glycine) were added to stop the reaction, and the azoderivatives were extracted with 2 vol of 2-pentanone. The extracted azodipyrroles were analyzed by TLC and measured spectrophotometrically (27). For analysis of radioactivity in each individual conjugated dipyrrylmethene A or B moiety, methylated and fully acetylated derivatives of the conjugated azopigments were prepared and the isomeric azoderivatives A and B separated by TLC (26). Preparation of samples for measurement of ${ }^{14} \mathrm{C}$ or ${ }^{3} \mathrm{H}$ radioactivity (Beckman liquid scintillation spectrometer model LS250, Beckman Instruments Inc., Fullerton, Calif.) and data analysis was carried out as described (9). Dual-label $\left({ }^{14} \mathrm{C}\right.$ 
and ${ }^{3} \mathrm{H}$ ) counting and correction of count rates was performed as detailed in Beckman Biomedical Technical Report TR-586.

\section{Specific experiments}

Details of the experiments (series I-III) outlined in $E x$ perimental approach are given below.

Series $I$. In eight normal rats provided with an external bile fistula, endogenous BMG and BDG excretion in bile during a l-h control period was determined, and it was assumed that this rate of pigment excretion was maintained for the following $3 \mathrm{~h}$. The animals were injected intravenously with $13-70 \mathrm{nmol}$ of bilirubin-III $\alpha$ or $-\mathrm{XIII} \alpha\left[{ }^{14} \mathrm{C}\right]$ monoglucuronide $(8,880 \mathrm{dpm} / \mathrm{nmol})$ and an equal amount of unlabeled monoglucuronide of the opposite isomeric type (XIII $\alpha$ or III $\alpha$ ) (Table I). Bile was collected for 2 or $3 \mathrm{~h}$ and recovery of injected ${ }^{14} \mathrm{C}$ label in bile was determined. The intact glucuronides were extracted from bile and the radioactivity in the separated BMG and BDG was measured. A portion of the isolated BMG and $B D G$ was converted to ethyl anthranilate azoderivatives and the azodipyrrole glucuronide (azopigment- $\delta$ ) was isolated and converted to its methylated and fully acetylated derivative. The latter dipyrrolic pigment consisted of a mixture of the two isomeric forms of azodipyrrole 1-O-acyl-glucuronide, corresponding to the dipyrrylmethene parts $\mathrm{A}$ and $\mathrm{B}$ of the parent tetrapyrroles; in their methylated and acetylated forms, these two isomers can be separated by TLC for determination of radioactivity. ${ }^{14} \mathrm{C}$ activity in isomer $\mathrm{A}$ or $\mathrm{B}$ is expressed as a percentage of total radioactivity in the two isomers. Analysis of synthesized bilirubin-III $\alpha$ or $-\mathrm{XIII} \alpha\left[{ }^{14} \mathrm{C}\right]$ monoglucuronide showed that a trace amount of the ${ }^{14} \mathrm{C}$ label was associated with the dipyrrylmethene that, on the basis of the purity of the substrates used, had been expected to be unlabeled. This contamination, which ranged from 1-5\% (Table II, predicted distribution of radioactivity in UDPGlcUA-dependent mechanism) in part may have been due to hydrolysis during chromatography and in part to chromatographic streaking; the latter was implied by the observation that contamination was more pronounced with the III $\alpha\left[{ }^{14} \mathrm{C}\right]$ monoglucuronide whose radiolabeled azodipyrrolic isomer $\mathrm{B}$ moves chromatographically ahead of the unlabeled isomer $\mathbf{A}$.
Ancillary experiments were carried out to ascertain that conjugation and biliary excretion of bilirubin-III $\alpha$ and -XIII $\alpha$ and their monoglucuronides are comparable to those of the corresponding IX $\alpha$ isomers. $\left[{ }^{14} \mathrm{C}\right]$ bilirubin-III $\alpha,-\mathrm{IX} \alpha,-\mathrm{XIII} \alpha$ $(30-60 \mathrm{nmol})$ was administered to normal or homozygous Gunn rats and biliary excretion of these three isomers determined as described (29). In addition, excretion in bile of ${ }^{3} \mathrm{H}$ - and ${ }^{14} \mathrm{C}$-labeled $\mathrm{BMG}$ and $\mathrm{BDG}$ was measured in four rats injected intravenously with a mixture of 75-90 nmol of $\left[{ }^{14} \mathrm{C}\right]$ bilirubin-III $\alpha$ or $-\mathrm{XIII} \alpha$ monoglucuronide and an equal amount of $\left[{ }^{3} \mathrm{H}\right]$ bilirubin monoglucuronide. Aliquots of consecutively collected bile samples were radioassayed to estimate recovery of isotope in bile.

The distribution of ${ }^{3} \mathrm{H}$ and ${ }^{14} \mathrm{C}$ label between $\mathrm{BMG}$ and BDG was determined by the ethyl anthranilate and alkaline methanolysis methods.

Series II. After a control period of $2 \mathrm{~h}$, three SpragueDawley rats provided with an external bile fistula were injected intravenously with $1.7 \mu \mathrm{mol}$ of unlabeled bilirubin and $33 \mathrm{nmol}$ of $\left[{ }^{3} \mathrm{H}\right]$ bilirubin $\left[{ }^{14} \mathrm{C}\right]$ monoglucuronide, and bile was collected for $2 \mathrm{~h} .{ }^{14} \mathrm{C}$ and ${ }^{3} \mathrm{H}$ in aliquots of bile were measured for estimation of recovery of the injected labels, and total (labeled and unlabeled) BMG and BDG excreted in bile were determined both by the ethyl anthranilate and the alkaline methanolysis methods. The intact glucuronides were extracted from the bile and from an aliquot of the administered sample; BMG and BDG were isolated by TLC and their content of ${ }^{14} \mathrm{C}$ and ${ }^{3} \mathrm{H}$ was measured.

Series III. After a control period of $2-3 \mathrm{~h}$, five homozygous Gunn rats (group A) were infused intravenously over 15 min with $\sim 0.5 \mu \mathrm{mol}$ of BMG. Bile was collected for $1 \mathrm{~h}$ after the start of the infusion, and the pigment in bile and an aliquot of the injected sample were analyzed by the alkaline methanolysis and ethyl anthranilate methods. Recovery of the injected pigment in bile was determined by the ethyl anthranilate method. Another five Gunn rats (group B) were injected with a small dose of $\left[{ }^{14} \mathrm{C}\right] \mathrm{BMG}(16-38 \mathrm{nmol} ; 13.5 \mathrm{dpm} / \mathrm{pmol})$, given as a bolus. Bile was collected for the subsequent hour, the ${ }^{14} \mathrm{C}$ in aliquots of the bile was measured for estimation of recovery of the injected radioactivity, and after addition of appropriate carrier pigments, the ${ }^{14} \mathrm{C}$ content of the isolated

TABLE I

Experimental Details for Experiments of Series I

\begin{tabular}{|c|c|c|c|c|c|c|c|c|}
\hline \multirow[b]{2}{*}{ Rat } & \multicolumn{2}{|c|}{$\begin{array}{l}\text { Endogenous } \\
\text { bilirubin } \\
\text { glucuronides } \\
\text { excreted in bile } \\
\text { in } 2 \mathrm{~h}\end{array}$} & \multicolumn{4}{|c|}{ Injected authentic BMG } & \multicolumn{2}{|c|}{$\begin{array}{c}{ }^{14} \mathrm{C} \text {-Labeled } \\
\text { glucuronides } \\
\text { excreted in bile } \\
\text { in } 2 \mathrm{~h}\end{array}$} \\
\hline & Total & BDC, & $\mathrm{A}-$ (1) * & B-(B)* & $\mathrm{A}-(\mathbb{1}$ & B-(B) & recovered & BDG, \\
\hline & nmol & $\%$ & \multicolumn{4}{|c|}{ nmol } & $\%$ & $\%$ \\
\hline $1, W$ & 264 & 50 & 32 & & & 32 & 91 & 42 \\
\hline $2, W$ & 338 & 58 & 32 & & & 32 & 97 & 61 \\
\hline $3, \mathrm{SD}$ & 293 & 67 & 43 & & & 43 & 81 & 66 \\
\hline $4, \mathrm{SD}$ & 282 & 51 & 43 & & & 43 & 88 & 37 \\
\hline $5, \mathrm{~W}$ & 340 & 60 & & 13 & 13 & & 93 & 51 \\
\hline $6, \mathrm{SD}$ & 185 & 55 & & 45 & 45 & & 94 & 26 \\
\hline $7, \mathrm{SD}$ & 400 & 58 & & 70 & 70 & & 86 & 43 \\
\hline $8, S D$ & 286 & 49 & & 58 & 58 & & 80 & 25 \\
\hline
\end{tabular}

Abbreviations used in this table: A-A, bilirubin-XIII $\alpha$; B-B, bilirubin-III $\alpha$; (A or (B), dipyrrylmethene part $\mathrm{A}$ or $\mathrm{B}$ that is esterified with glucuronic acid; (A)* or (B)*, dipyrrylmethene part A or B that is esterified with ${ }^{14} \mathrm{C}$-labeled glucuronic acid; W, Wistar; SD, Sprague-Dawley. 
TABLE II

Distribution of ${ }^{14} \mathrm{C}$ in BDG Excreted in Bile after Injection of Bilirubin-III $\alpha$, or -XIII $\alpha\left[{ }^{14} \mathrm{C}\right]$ Monoglucuronide in Normal Rats (Series I)

\begin{tabular}{|c|c|c|c|c|c|c|c|c|}
\hline \multirow[b]{5}{*}{ Rat } & \multicolumn{8}{|c|}{${ }^{14} \mathrm{C}$ in dipyrrylmethene $\mathrm{A}$ or $\mathrm{B}$ of $\mathrm{BDG}$ in bile } \\
\hline & \multicolumn{4}{|c|}{ Predicted distribution } & \multirow{2}{*}{\multicolumn{4}{|c|}{ Observed distribution }} \\
\hline & \multirow{2}{*}{\multicolumn{2}{|c|}{ Transglucuronidation }} & \multirow{2}{*}{\multicolumn{2}{|c|}{$\begin{array}{l}\text { UDPGlcUA- } \\
\text { dependent }\end{array}$}} & & & & \\
\hline & & & & & \multicolumn{2}{|c|}{ BDG } & \multicolumn{2}{|c|}{ BMG } \\
\hline & A & B & A & B & A & B & A & B \\
\hline & \multicolumn{2}{|c|}{$\%$} & \multicolumn{2}{|c|}{$\%$} & \multicolumn{2}{|c|}{$\%$} & \multicolumn{2}{|c|}{$\%$} \\
\hline $1, \mathrm{~W}$ & $67-75$ & $25-33$ & 99 & 1 & 99 & 1 & 99 & 1 \\
\hline $2, \mathrm{~W}$ & $67-75$ & $25-33$ & 99 & 1 & 99 & 1 & 97 & 3 \\
\hline $3, \mathrm{SD}$ & $67-75$ & $25-33$ & 99 & 1 & 99 & 1 & 99 & 1 \\
\hline $4, \mathrm{SD}$ & $67-75$ & $25-33$ & 99 & 1 & 99 & 1 & 99 & 1 \\
\hline $5, \mathrm{~W}$ & $17-25$ & $75-83$ & 2 & 98 & 3 & 97 & 4 & 96 \\
\hline $6, \mathrm{SD}$ & $17-25$ & $75-83$ & 5 & 95 & 5 & 95 & 6 & 94 \\
\hline 7,SD & $17-25$ & $75-83$ & 3 & 97 & 2 & 98 & 1 & 99 \\
\hline $8, \mathrm{SD}$ & $17-25$ & $75-83$ & 3 & 97 & 3 & 97 & 4 & 96 \\
\hline
\end{tabular}

Abbreviations explained in Table I.

mono- and diconjugated pigment fractions was determined. In an additional experiment, two Gunn rats were injected in the tail vein with $140 \mathrm{nmol}$ of $\left[{ }^{14} \mathrm{C}\right]$ bilirubin $(4.0 \mathrm{dpm} / \mathrm{pmol})$ to prelabel their endogenous bilirubin pool (30). $18 \mathrm{~h}$ later, the animals were provided with cannulae in a jugular vein and the bile duct and after a control period of $2 \mathrm{~h}$, a blood sample was taken for determination of the concentration and specific activity of serum bilirubin. Unlabeled BDG $(8.5 \mu \mathrm{mol})$ was then infused intravenously over $15 \mathrm{~min}$ and bile collected for $2 \mathrm{~h}$. To determine the specific activities of the excreted BMG and BDG, the corresponding mono- and dimethyl esters obtained by alkaline methanolysis were saponified individually (25); bilirubin thus formed was isolated by TLC (24) and its specific activity determined. $2 \mathrm{~h}$ after administration of the BDG, the rats were anesthetized with ether and exsanguinated. For determination of the specific activity of serum bilirubin, a serum sample was subjected to alkaline methanolysis, bilirubin isolated from the extract by TLC (24), and its specific activity determined.

\section{RESULTS}

\section{Experimental series I}

Comparison of the conjugation and biliary excretion of the bilirubin isomers III $\alpha, I X \alpha$, and XIII $\alpha$. After injection of ${ }^{14} \mathrm{C}$-labeled bilirubin-III $\alpha$ or -XIII $\alpha$ in four Wistar rats, $75-88 \%$ of the label of the administered III $\alpha$ isomer and $75 \%$ of that of the XIII $\alpha$ isomer appeared in bile collected over the subsequent $3 \mathrm{~h}$. Approximately half ( $52 \%$ for the III $\alpha$ isomer and $49-59 \%$ for the XIII $\alpha$ isomer) of the label was excreted as BDG. In two Gunn rats, only 4 and 5\%, respectively, of injected III $\alpha$ or XIII $\alpha$ isomer was recovered in bile in $3 \mathrm{~h}$ and bilirubin glucuronides could not be detected. These results are similar to those obtained with bilirubin (29), and show that Gunn rats are unable to conjugate bilirubin-III $\alpha$ and -XIII $\alpha$. In four SpragueDawley rats injected with equal amounts of $\left[{ }^{3} \mathrm{H}\right] b i \mathrm{li}-$ rubin monoglucuronide and either $\left[{ }^{14} \mathrm{C}\right]$ bilirubinIII $\alpha$ or -XIII $\alpha$ monoglucuronide, recovery of ${ }^{14} \mathrm{C}$ in the bile collected for $2 \mathrm{~h}$ ranged from 81 to $91 \%$ of the administered dose; the corresponding values for ${ }^{3} \mathrm{H}$ recovery were $74-90 \%$. Conversion of the III $\alpha$ and $\mathrm{XIII} \alpha$ isomers to their diglucuronides and their excretion in bile were comparable to those for the co-injected IX $\alpha$ isomer (Fig. 4). These findings indicated that the III $\alpha$ and XIII $\alpha$ isomers of bilirubin are metabolized by the liver like bilirubin, justifying their use as model compounds in the following experiments.

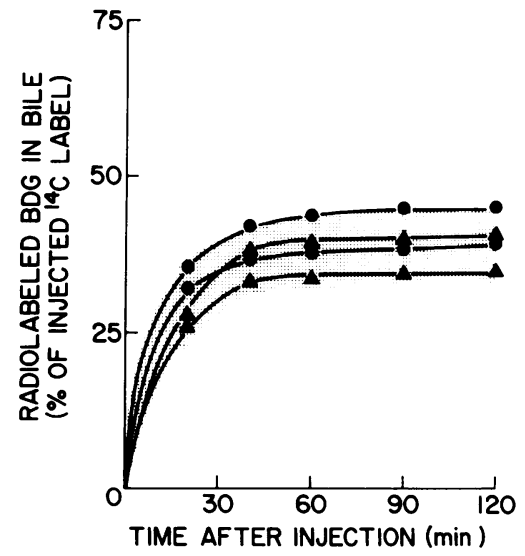

FIGURE 4 Comparison of biliary excretion of diglucuronides formed from isomeric (III $\alpha, \mathrm{IX} \alpha, \mathrm{XIII} \alpha$ ) bilirubin monoglucuronides in Sprague-Dawley rats. The shaded area represents cumulative excretion (mean $\pm 2 \mathrm{SD}$ ) of ${ }^{3} \mathrm{H}$-labeled BDG after administration of $\left[{ }^{3} \mathrm{H}\right]$ bilirubin monoglucuronide in four animals. The curves indicate cumulative excretion of ${ }^{14} \mathrm{C}$ labeled BDG formed from injected $\left[{ }^{14} \mathrm{C}\right]$ bilirubin-III $\alpha(\bullet)$, or $-\mathrm{XIII} \alpha(\Delta)$ monoglucuronide in individual rats. 
Diglucuronide formation from injected III $\alpha$ and XIII $\alpha$ monoglucuronides in normal rats. When bilirubin-III $\alpha$ or -XIII $\alpha\left[{ }^{14} \mathrm{C}\right]$ monoglucuronide (Figs. 1 and 2) was injected in Wistar or Sprague-Dawley rats, 80 $97 \%$ of the radioactivity was recovered in bile in $2 \mathrm{~h}$; $25-66 \%$ of the excreted labeled glucuronides were diglucuronides, indicating that significant conversion of injected BMG to BDG had occurred (Table I). The distribution of the labeled glucuronosyl group in the excreted BDG with regard to its attachment to either dipyrrylmethene A or B was virtually identical with that in the injected BMG, as expected for a UDPGlcUAdependent mechanism (Table II). The results are inconsistent, however, with a transglucuronidation mechanism (Table II).

\section{Experimental series $I I$}

Conversion of $\left[{ }^{3} \mathrm{H}\right]$ bilirubin $\left[{ }^{14} \mathrm{C}\right]$ monoglucuronide to diglucuronide in Sprague-Dawley rats. When $\left[{ }^{3} \mathrm{H}\right]$ bilirubin $\left[{ }^{14} \mathrm{C}\right]$ monoglucuronide was injected in three rats, $75-81 \%$ of each label was excreted in bile in the initial $30 \mathrm{~min}$ (Table III). During the subsequent $30-\mathrm{min}$ period, only an additional $2-4 \%$ of each label was excreted. The BDG fraction contained $29-36 \%$ of the excreted ${ }^{14} \mathrm{C}$ and $33-40 \%$ of the ${ }^{3} \mathrm{H}$, indicating that extensive conversion of injected $\mathrm{BMG}$ to BDG had occurred (Table III). The ${ }^{14} \mathrm{C}:{ }^{3} \mathrm{H}$ ratio of the BMG in bile was identical to that in the administered pigment, whereas the ratio in BDG ranged from 0.78 to 0.91 of that in the injected BMG (Table III). The slightly lower recovery of ${ }^{14} \mathrm{C}$ compared to ${ }^{3} \mathrm{H}$ in bile, and the ${ }^{14} \mathrm{C}:{ }^{3} \mathrm{H}$ ratio below unity in the excreted BDG (Table III) indicate that a small fraction of the glucuronides had been hydrolyzed. If this hydrolysis is taken into account, the isotope ratio of the excreted BMG and BDG is comparable to that predicted for a UDP-glucuronosyltransferase mechanism, but different from the isotope ratio expected on the basis of a transglucuronidation reaction (Table III, Fig. 3).

\section{Experimental series III}

Excretion of injected BMG in Gunn rats. The administered pigment solution contained 90-95\% authentic BMG, the remainder being made up of small amounts of bilirubin and BDG (Table IV). In the five rats (group A) given a large dose of unlabeled BMG, the average recovery of the injected pigment in $1 \mathrm{~h}$ was $96 \%$. The corresponding value in the five animals (group B) that received a tracer dose of ${ }^{14} \mathrm{C}$-labeled BMG was $85 \%$ (Table IV). In all 10 rats the pattern of the excreted glucuronides, determined by two analytical methods, was similar to that of the injected conjugates, indicating that conversion of BMG to BDG had not occurred.

Excretion of injected $B D G$ and $\left[{ }^{14} C\right]$ bilirubin in Gunn rats. When unlabeled BDG was injected into two Gunn rats whose endogenous bilirubin pool had been labeled with ${ }^{14} \mathrm{C}, 75-85 \%$ of the administered unlabeled pigment was recovered in bile in $2 \mathrm{~h}$ (Table V). Of this, 94\% was BDG and 6\% B.MG (Table V). Since virtually no label was present in the excreted BMG, it obviously had been formed by hydrolysis of the injected BDG. These findings are incompatible with a reverse transglucuronidation mechanism.

\section{DISCUSSION}

The present study was made possible by the application of new and improved methods for preparation and

TABLE III

Conversion of Injected $\left[{ }^{3} \mathrm{H}\right]$ Bilirubin $\left[{ }^{14} \mathrm{C}\right]$ Monoglucuronide to BDG in Sprague-Dawley Rats (Series II)

\begin{tabular}{|c|c|c|c|c|c|c|c|c|c|c|c|c|}
\hline \multirow[b]{5}{*}{ Rat } & & & & & \multicolumn{8}{|c|}{ Radiolabeled glucuronides in bile* } \\
\hline & & & & & & & & & ${ }^{14} \mathrm{C}:{ }^{3} \mathrm{I}$ & ratiof & & \\
\hline & & & & & & & & Pre & ted & & & \\
\hline & \multicolumn{2}{|c|}{$\begin{array}{l}\text { Glucuronides } \\
\text { in bile* }\end{array}$} & \multicolumn{2}{|c|}{$\begin{array}{c}\text { Radiolabel } \\
\text { in bile* }\end{array}$} & \multicolumn{2}{|c|}{$\begin{array}{c}\text { Radiolabeled } \\
\text { BDG }\end{array}$} & \multicolumn{2}{|c|}{$\begin{array}{l}\text { Transglucuron- } \\
\text { idation }\end{array}$} & \multicolumn{2}{|c|}{$\begin{array}{l}\text { UDPGlcLA- } \\
\text { dependent }\end{array}$} & \multicolumn{2}{|c|}{ Found } \\
\hline & Total & BDG & ${ }^{14} \mathrm{C}$ & ${ }^{3} \mathbf{H}$ & {$\left[{ }^{14} \mathrm{C}\right] \mathrm{BDG}$} & {$\left[{ }^{3} \mathrm{H}\right] \mathrm{BDG}$} & BMG & BDG & BMG & $\mathrm{BDG}$ & B.MG & BDG \\
\hline & nmol & $\%$ & & & & & & & & & & \\
\hline 1 & 1,205 & 55 & 81 & 88 & 36 & 40 & 0.72 & 1.44 & 1.0 & 1.0 & 0.98 & 0.78 \\
\hline 2 & 1,257 & 51 & 78 & 92 & 31 & 35 & 0.72 & 1.44 & 1.0 & 1.0 & 1.0 & 0.81 \\
\hline 3 & 1,317 & 60 & 75 & 83 & 29 & 33 & 0.72 & 1.44 & 1.0 & 1.0 & 0.98 & 0.91 \\
\hline
\end{tabular}

* Bile collected during the first 30 min after injection of pigment.

$\$$ The ${ }^{14} \mathrm{C}:{ }^{3} \mathrm{H}$ ratio in $\mathrm{BMG}$ and $\mathrm{BDG}$ excreted in bile is expressed as a fraction of the ratio in injected BMG. 
TABLE IV

Biliary Excretion of Injected BMG in Homozygous Gunn Rats (Series III)

\begin{tabular}{|c|c|c|c|c|c|c|}
\hline & \multicolumn{3}{|c|}{ Bilirubin glucuronides injected } & \multicolumn{3}{|c|}{ Glucuronides excreted in bile in $1 \mathrm{~h}$} \\
\hline & \multirow[b]{2}{*}{ Total } & \multicolumn{2}{|c|}{ Authentic BMG* } & \multirow[b]{2}{*}{ Recovered* } & \multicolumn{2}{|c|}{ BMG* } \\
\hline & & AM & EA & & AM & EA \\
\hline & nmol & & & $\%$ & & \\
\hline Group A $(n=5)$ & $476-589$ & $92 \pm 1$ & $95 \pm 2$ & $96 \pm 3$ & $93 \pm 2$ & $96 \pm 3$ \\
\hline Group B $(n=5)$ & $16-38$ & $90 \pm 3$ & ND & $85 \pm 9$ & $91 \pm 4$ & ND \\
\hline
\end{tabular}

Abbreviations used in this table: AM, determined by the alkaline methanolysis method; EA, determined by the ethyl anthranilate method; ND, not done.

* Mean \pm SD.

analysis of bilirubin conjugates $(9,17,24,26-28)$, which had not been available previously. These procedures included preparation of BMG containing 85-95\% authentic monoglucuronide, which represents a substantially smaller contamination with unconjugated bilirubin and BDG than had previously been achieved $(10,11,18,19)$. They also made it possible to prepare dual-labeled $\mathrm{BMG}$ containing ${ }^{3} \mathrm{H}$ in the tetrapyrrolic aglycone and ${ }^{14} \mathrm{C}$ in the glucuronosyl moiety, and $\left[{ }^{14} \mathrm{C}\right]-$ monoglucuronides of the bilirubin-III $\alpha$ and -XIII $\alpha$ isomers. Moreover, a novel, accurate method was employed for specific measurement of bilirubin and its mono- and diglucuronides (9). This assay represents a considerably improvement over previously available procedures, including the ethyl anthranilate method (27) which may overestimate monoconjugates, particularly in pigment samples containing a relatively large amount of unconjugated bilirubin or when the prescribed requirements for sample dilution or $\mathrm{pH}$ control in the diazo-reaction are not rigidly observed (for a discussion, see $15,27,31$ ).

Using these new experimental tools, we have demonstrated that in normal rats, injected bilirubin glucuronides are rapidly and almost quantitatively excreted in bile (Tables I and III). A substantial fraction of the administered BMG is converted into BDG, as had previously been reported by Ostrow and Murphy (18). It was noted, however, that the fraction of injected BMG that appeared in the bile as BDG was smaller than expected on the basis of the endogenous BDG excretion in normal rat bile (Tables I and III). This suggests that administered BMG does not mix completely with BMG endogenously formed in the liver.

In jaundiced Gunn rats from two different colonies, injected bilirubin glucuronides were excreted in amounts comparable to those in normal rats, but no conversion of BMG to BDG could be detected (Tables I and III-V). Whereas these results are in agreement with previous observations (18), they differ from those of Chowdhury et al., who reported that in Gunn rats the rate of biliary excretion of injected glucuronides is considerably smaller than in normal rats and administered BMG in part is excreted as BDG (11). The reasons for these divergent findings are not apparent.

An incidental observation was that a minor fraction of the injected bilirubin glucuronides was hydrolyzed. In normal rats given dual-labeled $\mathrm{BMG}$, this was apparent from the smaller recovery in bile of ${ }^{14} \mathrm{C}$, contained in the glucuronosyl moiety, as compared to ${ }^{3} \mathrm{H}$ in the tetrapyrrolic aglycone of the excreted glucuronides (Table III). The isotope ratios of the individual BMG and BDG fractions in bile suggested that hydrolysis particularly affected BDG. Similarly, infusion of BDG in Gunn rats resulted in excretion of $\sim 6 \% \mathrm{BMG}$

TABLE V

Biliary Excretion of Injected BDG in Gunn Rats Prelabeled with $\left[{ }^{14} \mathrm{C}\right]$ Bilirubin

\begin{tabular}{|c|c|c|c|c|c|c|c|c|}
\hline \multirow[b]{3}{*}{ Rat } & \multicolumn{3}{|c|}{ Serum bilirubin } & \multicolumn{5}{|c|}{ Glucuronides excreted in bile } \\
\hline & \multirow[b]{2}{*}{ Time $0^{*}$} & \multicolumn{2}{|c|}{ Specific activity } & \multirow[b]{2}{*}{ Recovery in $2 \mathrm{~h}$} & \multicolumn{2}{|c|}{ Composition } & \multicolumn{2}{|c|}{ Specific activity } \\
\hline & & Time 0 & $2 \mathrm{~h}$ & & BMG & BDG & BMG & BDG \\
\hline & $\mu M$ & \multicolumn{2}{|c|}{$d p m / n m o l$} & $\%$ injected $B D G$ & \multicolumn{2}{|c|}{$\%$} & \multicolumn{2}{|c|}{$d p m / n m o l$} \\
\hline 1 & 149 & 28 & 28 & 75 & 7 & 93 & $<1$ & 0 \\
\hline 2 & 101 & 35 & 37 & 85 & 6 & 94 & $<1$ & 0 \\
\hline
\end{tabular}

* Time at which intravenous infusion of BDG was started. 
formed by hydrolysis of the administered pigment (Table V). Previous observations obtained by different experimental approaches had also suggested that bilirubin glucuronides may undergo deconjugation in the liver $(32,33)$.

The objective of this study was to clarify the mechanism of the conversion of BMG to BDG in intact rats. For this purpose, the pattern of bilirubin glucuronides excreted in bile was determined in rats injected either with bilirubin-III $\alpha$ or $-\mathrm{XIII} \alpha\left[{ }^{14} \mathrm{C}\right]$ monoglucurunide or with $\left[{ }^{3} \mathrm{H}\right]$ bilirubin $\left[{ }^{14} \mathrm{C}\right]$ monoglucuronide. While analysis of the labeled pigment conjugates in bile obviously does not permit direct assessment of the nature of the underlying enzymatic events, the present experiments were designed so that the results would exclude one of the two postulated mechanisms for BDG formation $(10,17)$. It is evident that the results listed in Tables II and III rule out a transglucuronidation mechanism (10), but are consistent with a UDPGlcUAdependent enzyme system (17). These findings and the present observation that homozygous Gunn rats in vivo cannot convert injected BMG to BDG are in agreement with the demonstrations in vitro that rat $(17,34)$ and cat liver (19) contain a microsomal UDP-glucuronosyltransferase system which readily converts bilirubin or BMG to BDG. Further, albeit indirect, support for the in vivo operation of this system is provided by the observations that the proportion of BMG in bile is increased in conditions associated with deficient hepatic UDP-glucuronosyltransferase activity, such as the Crigler-Najjar disease, Gilbert syndrome, and heterozygous Gunn rats $(9,14-16)$, and in normal humans (12) and rats $(9,13)$ infused with large amounts of bilirubin. These phenomena appear incompatible with a transglucuronidation mechanism whose activity in rat liver has been reported to be considerably higher than that of UDP-glucuronosyltransferase $(10,11)$. Based on the previous in vitro $(17,34)$ and present in vivo findings, we conclude that hepatic formation of both BMG and BDG most likely is catalyzed by a microsomal UDP-glucuronosyltransferase system.

\section{ACKNOWLEDGMENTS}

We are indebted to Dr. A. F. McDonagh for a critical review of the manuscript, and to L. Beausoleil and D. Fedorchak for excellent editorial assistance.

This work was supported in part by National Institutes of Health Research Grants AM-21899, AM-11275, and P50 AM18520 .

\section{REFERENCES}

1. Schmid, R., and A. F. McDonagh. 1978. Hyperbilirubinemia. In The Metabolic Basis of Inherited Disease. J. B. Stanbury, J. B. Wyngaarden, and D. S. Frederickson, editors. McGraw-Hill Book Co., Inc., New York. 12211257.

2. Gordon, E. R., C. A. Goresky, T. -H. Chan, and A. S.
Perlin. 1976. The isolation and characterization of bilirubin diglucuronide, the major bilirubin conjugate in dog and human bile. Biochem. J. 155: 477-486.

3. Compernolle, F., G. P. Van Hees, N. Blanckaert, and K. P. M. Heirwegh. 1978. Glucuronic acid conjugates of bilirubin-IX $\alpha$ in normal bile compared to obstructive bile. Transformation of the 1-O-acylglucuronide into 2-, 3-, and 4-O-acylglucuronides. Biochem. J. 171: 185-201.

4. Schmid, R. 1978. Bilirubin metabolism: State of the art. Gastroenterology. 74: 1307-1312.

5. Dutton, G. J. 1966. The biosynthesis of glucuronides. In Glucuronic Acid. Free and Combined. G. J. Dutton, editor. Academic Press, Inc., New York. 185-299.

6. Heirwegh, K. P. M., J. A. T. P. Meuwissen, and J. Fevery. 1973. Critique of the assay and significance of bilirubin conjugation. Adv. Clin. Chem. 16: 239-289.

7. Fevery, J., M. Van De Vijver, R. Michiels, and K. P. M. Heirwegh. 1977. Comparison in different species of biliary bilirubin-IX $\alpha$ conjugates with the activities of hepatic and renal bilirubin-IX $\alpha$-uridine diphosphate glycosyltransferases. Biochem. J. 164: 737-746.

8. Jansen, F. H., and B. H. Billing. 1971. The identification of monoconjugates of bilirubin in bile as amide derivatives. Biochem. J. 125: 917-919.

9. Blanckaert, N. 1980. Analysis of bilirubin and bilirubin mono- and diconjugates. Determination of their relative amounts in biological fluids. Biochem. J. 185: 115-128.

10. Jansen, P. L. M., J. R. Chowdhury, E. B. Fischberg, and I. M. Arias. 1977. Enzymatic conversion of bilirubin monoglucuronide to diglucuronide by rat liver plasma membranes. J. Biol. Chem. 252: 2710-2716.

11. Chowdhury, J. R., P. L. M. Jansen, E. B. Fischberg, A. Daniller, and I. M. Arias. 1978. Hepatic conversion of bilirubin monoglucuronide to diglucuronide in uridine diphosphate-glucuronosyltransferase-deficient man and rat by bilirubin glucuronoside glucuronosyltransferase. J. Clin. Invest. 62: 191-196.

12. Schalm, L., and A. P. Weber. 1962. De bilirubinepigmenten in bloed en gal na belasting met bilirubine bij de mens. Ned. Tijdschr. Geneesk. 106: 1079-1084.

13. Noir, B. A. 1976. Bilirubin conjugates in bile of man, rat and dog. Semi-quantitative analysis of bile composition by thin-layer chromatography. Biochem. J. 155: 365-373.

14. Gollan, J. L., S. N. Huang, B. H. Billing, and S. Sherlock. 1975. Prolonged survival in three brothers with severe type 2 Crigler-Najjar syndrome. Ultrastructural and metabolic studies. Gastroenterology. 68: 1543-1555.

15. Fevery, J., N. Blanckaert, K. P. M., Heirwegh, A.-M. Preaux, and P. Berthelot. 1977. Unconjugated bilirubin and an increased proportion of bilirubin monoconjugates in the bile of patients with Gilbert syndrome and CriglerNajjar disease. J. Clin. Invest. 60: 970-979.

16. Goresky, C. A., E. R. Gordon, E. A. Shaffer, P. Pare, D. Carassavas, and A. Aronoff. 1978. Definition of a conjugation dysfunction in Gilbert's syndrome: studies of the handling of bilirubin loads and of the pattern of bilirubin conjugates secreted in bile. Clin. Sci. Mol. Med. 55: 63-71.

17. Blanckaert, N., J. Gollan, and R. Schmid. 1979. Bilirubin diglucuronide synthesis by a UDP-glucuronic acid-dependent enzyme system in rat liver microsomes. Proc. Natl. Acad. Sci. U. S. A. 76: 2037-2041.

18. Ostrow, J. D., and N. H. Murphy. 1970. Isolation and properties of conjugated bilirubin from bile. Biochem. J. 120: $311-327$.

19. Jansen, P. L. M. 1974. The enzyme-catalyzed formation of bilirubin diglucuronide by a solubilized preparation from cat liver microsomes. Biochim. Biophys. Acta. 338: $170-182$. 
20. Carbone, J. V., and G. M. Grodsky. 1957. Constitutional nonhemolytic hyperbilirubinemia in the rat: Defect of bilirubin conjugation. Proc. Soc. Exptl. Biol. Med. 94: $561-463$.

21. Schmid, R., J. Axelrod, L. Hammaker, and R. L. Swarm. 1958. Congenital jaundice in rats, due to a defect in glucuronide formation. J. Clin. Invest. 37: 1123-1130.

22. Chowdhury, J. R., N. R. Chowdhury, M. Bhargava, and I. M. Arias. 1979. Bilirubin glucuronide glucuronosyltransferase: purification, characterization and function. Gastroenterology. 76: 1277. (Abstr.)

23. Ostrow, J. D., L. Hammaker, and R. Schmid. 1961. The preparation of crystalline bilirubin- $\mathrm{C}^{14}$ J. Clin. Invest. 40: 1442-1452.

24. McDonagh, A. F., and F. Assisi. 1971. Commercial bilirubin: a trinity of isomers. FEBS (Fed. Eur. Biochem. Soc.) Lett. 18: 315-317.

25. Blanckaert, N., K. P. M. Heirwegh, and F. Compernolle. 1976. Synthesis and separation by thin-layer chromatography of bilirubin isomers. Their identification as tetrapyrroles and dipyrrolic ethyl anthranilate azo derivatives. Biochem. J. 155: 405-417.

26. Blanckaert, N., F. Compernolle, P. Leroy, R. Van Houtte, J. Fevery, and K. P. M. Heirwegh. 1978. The fate of bilirubin-IX $\alpha$ glucuronide in cholestasis and during storage in vitro. Intramolecular rearrangement to positional isomers of glucuronic acid. Biochem. J. 171: 203-214.

27. Heirwegh, K. P. M., J. Fevery, J. A. T. P. Meuwissen, J. De Groote, F. Compernolle, V. Desmet, and F. P. Van
Roy. 1975. Recent advances in the separation and analysis of diazo-positive bile pigments. Methods Biochem. Anal. 22: 205-250.

28. Blanckaert, N., J. Fevery, K. P. M. Heirwegh, and F. Compernolle. 1977. Characterization of the major diazopositive pigments in bile of homozygous Gunn rats. Biochem. J. 164: 237-249.

29. Blanckaert, N., K. P. M. Heirwegh, and Z. Zaman. 1977. Comparison of the biliary excretion of the four isomers of bilirubin-IX in Wistar and homozygous Gunn rats. Biochem. J. 164: 229-236.

30. Schmid, R., and L. Hammaker. 1963. Metabolism and disposition of ${ }^{14} \mathrm{C}$-bilirubin in congenital nonhemolytic jaundice. J. Clin. Invest. 42: 1720-1734.

31. Ostrow, J. D., and S. T. Boonyapisit. 1978. Inaccuracies in measurement of conjugated and unconjugated bilirubin in bile with ethyl anthranilate diazo and solvent-partition methods. Biochem. J. 173: 263-267.

32. Acocella, G., L. T. Tenconi, R. Armas-Merino, S. Raia, and B. H. Billing. 1968. Does deconjugation of bilirubin glucuronide occur in obstructive jaundice? Lancet. I: 68-69.

33. Campbell, M. T., and G. J. Dutton. 1979. The formation and distribution of bilirubin monoglucuronide and diglucuronide in rat liver slices. Biochem. J. 179: 473-477.

34. Gordon, E. R., and C. A. Goresky. 1978. The formation of bilirubin diglucuronide by microsomal preparations from the rat. Gastroenterology. 75: 966. (Abstr.) 